\title{
Physicochemical Properties and Digestion of Lotus Seed Starch under High-Pressure Homogenization
}

\author{
Zebin Guo ${ }^{1,2,3}$, , Beibei Zhao ${ }^{1,2,3}$, Liding Chen ${ }^{4}$ and Baodong Zheng ${ }^{1,2,3, *}$ \\ 1 College of Food Science, Fujian Agriculture and Forestry University, Fuzhou 350002, China; \\ gzb8607@163.com (Z.G.); nwzj151@163.com (B.Z.) \\ 2 Fujian Provincial Key Laboratory of Quality Science and Processing Technology in Special Starch, \\ Fujian Agriculture and Forestry University, Fuzhou 350002, China \\ 3 China-Ireland International Cooperation Centre for Food Material Science and Structure Design, \\ Fujian Agriculture and Forestry University, Fuzhou 350002, China \\ 4 College of life Science, Fujian Agriculture and Forestry University, Fuzhou 350002, China; \\ BioEngin_2015@126.com \\ * Correspondence: zbdfst@yeah.net; Tel.: +86-591-83789202
}

Received: 24 November 2018; Accepted: 4 February 2019; Published: 11 February 2019

\begin{abstract}
Lotus seed starch (LS), dispersed $(3 \%, w / v)$ in deionized water was homogenized (0-180 MPa) with high-pressure homogenization (HPH) for $15 \mathrm{~min}$. The effects of HPH treatment on the physicochemical properties of the starch system were investigated. The properties were affected by HPH to various extents, depending on the pressure. These influences can be explained by the destruction of the crystalline and amorphous regions of pressurized LS. The short-range order of LS was reduced by HPH and starch structure C-type was transformed into B-type, exhibiting lower transition temperatures and enthalpy. The LS absorbed a great deal of water under HPH and rapidly swelled, resulting in increased swelling power, solubility and size distribution. It then showed "broken porcelain-like" morphology with reduced pasting properties. Digestion of pressurized LS complex investigated by a dynamic in vitro rat stomach-duodenum model showed higher digestion efficiency and the residues exhibited gradual damage in morphology.
\end{abstract}

Keywords: high-pressure homogenization treatment; physicochemical properties; DIVRSD-II model; digestion properties

\section{Introduction}

Starch is a macromolecule compound composed of glucose. It can be extracted from starchy substances such as corn, lotus seed and sweet potato [1-3]. Lotus seed starch (LS) is commercially available in China and it is consumed as a traditional confectionery and food additive. Production of LS is rising year by year because of market demand. However, LS has a poor utilization rate because native starch has a high tendency toward retrogradation and inadequate storage stability at low temperatures [4]. Modified starch, with altered physicochemical properties to improve its functional characteristics, is used to tailor starch to specific food applications [5].

High-pressure homogenization (HPH), in which high pressures are applied over a very short time, involves synchronous application of cavitation, shear, turbulence and temperature rise induced by pressure [6]. Starch was shown to be partly gelatinized after HPH and the degree of gelatinization increased with homogenizing pressure-causing granule size changes [7]. Starches respond differently to HPH according to the pressure applied, starch concentration and source and treatment time. Various effects induced by pressure cause quality changes in starch [6]. However, the application of HPH and functional characteristics of starch have not been commonly studied, particularly with regard to digestion properties. 
Research on starch digestion includes in vivo and in vitro methods. The in vivo studies are costly, time-consuming and impeded by ethical issues even though they are relatively accurate ways to study functions of the gastrointestinal tract. In vitro simulation tests used to study digestion have a common flaw in that they oversimplify the gastrointestinal tract structure [8,9]. To solve these problems, a soft-elastic silicone rat stomach model was manufactured using 3D printing technology. An enhanced version of this "near-real" dynamic in vitro rat stomach system, DIVRSD-II (also called Biomimic Rat II, which incorporates the duodenum in a model stomach system) was recently introduced and its digestion of casein and coarse rice grains has proved similar to that of in vivo tests $[10,11]$. Moreover, the digestion behavior of DIVRSD-II on casein powder suspension is significantly affected by the gastrointestinal tract structure [10].

The published literature-with respect to the digestion properties of starch under HPH-is limited and focuses primarily on digestion rate. A comprehensive investigation addressing the structural changes occurring in starch-water systems before and after digestion is lacking. In this study, the effects of HPH on the physicochemical properties of LS were characterized by scanning electron microscopy (SEM), X-ray diffraction (XRD) measurements, laser diffraction particle size analysis, and Fourier transformed infrared spectroscopy (FTIR). At the same time, the viscosity, thermal properties, solubility and swelling power of homogenized starches were studied. Notably, the DIVRSD-II model was used to study the digestion efficiency of HPH-treated LS and the structural changes both before and after digestion were investigated, which will greatly help in clarifying the relationship between digestion and the structure of LS.

\section{Materials and Methods}

\subsection{Materials}

The LS (Green Field Fujian Food Co. Ltd., Fujian, China) was obtained according to Guo et al. [12], and contained on average (dry weight basis) $10.75 \%$ moisture, $0.29 \%$ ash, $0.32 \%$ protein, and $0.29 \%$ lipid.

\subsection{HPH Treatment}

A $3 \%(w / v)$ starch suspension was prepared by adding LS to deionized water at room temperature $\left(27 \pm 1^{\circ} \mathrm{C}\right)$. The well-mixed suspension was homogenized in a high-pressure homogenizer (FPG12805L; Stansted Fluid Power, UK) at 0, 60, 90, 120, 135, 150 and $180 \mathrm{MPa}$ for $15 \mathrm{~min}$, respectively. Approximately $500 \mathrm{~mL}$ of suspension was processed at each pressure level. The treated samples were freeze-dried (ALPHA 1-4/2-4 LSC plus; Germany christ Ltd., Osterode, Germany) for about $24 \mathrm{~h}$ with the condenser temperature at approximately $-80^{\circ} \mathrm{C}$, passed through a 100 -mesh sieve, then sealed and stored in a desiccator at room temperature.

\subsection{FTIR Analysis}

The FTIR spectra of starch samples were obtained using a Tensor 27 FTIR spectrometer (Bruker, Karlsruhe, Germany). To form a KBr pellet, $2 \mathrm{mg}$ of starch powder and $100 \mathrm{mg}$ of $\mathrm{KBr}$ were weighed and crushed in a quartz bowl. The spectra were scanned from 400 to $4000 \mathrm{~cm}^{-1}$ with 32 scanning times at resolution $4 \mathrm{~cm}^{-1}$.

\subsection{XRD}

Starch structures were determined using a D/max 2200PC X-ray diffractometer (Rigaku Corporation, Tokyo, Japan) at room temperature, with $\mathrm{Cu} \mathrm{K} \alpha$ radiation $(k=0.154 \mathrm{~nm})$. The patterns were obtained with a scanning range of $5-35^{\circ}$ and a scanning speed of $8^{\circ} \mathrm{min}^{-1}$.

\subsection{SEM Analysis}

A scanning electron microscope (JSM-6360LV, JEOL, Tokyo, Japan) was used to obtain morphology of starch samples, with the starch powder placed on the metal stub using double-sided glue. Morphology was observed under vacuum, with $20 \mathrm{keV}$ accelerating voltage. 


\subsection{SP and Solubility}

The starch suspensions $(2 \%, w / v)$ were prepared and heated in a boiling water bath with heating temperatures over $55-95{ }^{\circ} \mathrm{C}$ to obtain SP and solubility according to Guo et al. [13]. The heated sample was cooled and centrifuged $(4000 \times g$ for $10 \mathrm{~min})$. The precipitated and dried supernatant were weighed respectively. Each group was measured using the following formulae:

$$
\begin{gathered}
\mathrm{SP}=\frac{C}{A-B} \times 100 \% \\
\text { Solubility }=\frac{B}{A} \times 100 \%
\end{gathered}
$$

where B is dry weight of the supernatant, A is weight of the starch sample powder and C is mass of the precipitate.

\subsection{Laser Scattering Measurement}

A laser diffraction particle size analyzer (Malvern Mastersizer 3000, Malvern Instruments Ltd., England, UK) was used to assess starch granule size. Distilled water was the dispersant. Starch powder was dispersed in the cavity of the laser analyzer. Once the shading rate reached $8-15 \%$, the particle size was measured three times and averaged.

\subsection{Rapid Viscosity Analyzer (RVA) Analysis}

The $6 \%(w / v)$ starch suspensions were prepared and a RVA (TechMaster, Newport Scientific Pty. Ltd., Australia) used to determine their pasting properties according to Chen, et al., with a little modification [6]. Starch suspensions were equilibrated at $25^{\circ} \mathrm{C}$ for $1 \mathrm{~min}$ heated to $95^{\circ} \mathrm{C}$ at $5{ }^{\circ} \mathrm{C} \mathrm{min}-1$ and then cooled to $25^{\circ} \mathrm{C}$ at the same rate.

\subsection{Differential Scanning Calorimeter (DSC) Analysis}

A $2 \mathrm{mg}$ sample was added to the DSC pan and deionized water was added at a ratio of 1:2(w/v). Samples were equilibrated for $24 \mathrm{~h}$ at room temperature and then heated using a differential scanning calorimeter (DSC-200FC, NETZSCH, Selb, Germany) from $20{ }^{\circ} \mathrm{C}$ to $95{ }^{\circ} \mathrm{C}$ at $10{ }^{\circ} \mathrm{C} \mathrm{min}-1$, with an empty DSC pan used as a reference. The onset, peak, and conclusion temperatures were determined from the DSC gelatinization curve. The gelatinization enthalpy $(\Delta \mathrm{H})$ was calculated according to the peak area.

\subsection{In Vitro Digestion of HPH-Treated Starch in the DIVRSD-II Model}

Artificial rat saliva and gastric juice were prepared following the method of Chen et al. [10] and $\mathrm{Wu}$ et al. [14]. Artificial pancreatic juice and bile juice were prepared according to Wu et al. [15]. Glucose concentration was determined with a D-glucose assay kit (GOPOD-Format) (Megazyme International Ireland Ltd., Wicklow, Ireland). Gastric mucin and $\alpha$-amylase were obtained from Sigma (Sigma-Aldrich, Saint Louis, MO, USA). Amyloglucosidase, pancreatin, and pepsin were obtained from Solarbio (Shanghai Solarbio Bioscience \& Technology Co. Ltd., Shanghai, China). All other chemical reagents were obtained from Sinopharm Chemical Reagent Co. Ltd. (Beijing, China).

The DIVRSD-II model was applied to digestion of HPH-treated starch [15]. Starch samples (200 mg, dry basis) were dispersed in $2.0 \mathrm{~mL}$ of water and cooked for $15 \mathrm{~min}$ until gelatinized. Then $2.0 \mathrm{~mL}$ of artificial saliva $\left(37^{\circ} \mathrm{C}\right)$ was added to mimic oral digestion [16]. The food samples were digested in the DIVRSD-II model in batches as reported by Wu et al. [15] for 0, 10, 20, 30, 40, 50, 60, 90, 120 and $180 \mathrm{~min}$.

\subsection{Statistical Analyses}

Experimental diagrams were produced with Origin Pro 8.5. Data processing and significant difference analysis were performed with DPS 9.05191 (Science Press, Beijing, China). Differences among experimental mean values $(p<0.05)$ were determined by Duncan's multiple range test. 


\section{Results and Discussion}

\subsection{XRD Patterns}

The XRD patterns of LS subjected to HPH are shown in Figure 1. Native LS had strong diffraction peaks at $2 \theta$ values $\left(14.97^{\circ}, 16.99^{\circ}, 17.70^{\circ}\right.$ and $\left.22.80^{\circ}\right)$, indicating a C-type starch [13]. There were no marked changes in XRD patterns of starch granules for $60 \mathrm{MPa} H \mathrm{HP}$. However, as pressure increased, the intensity of diffraction peaks at $14.97^{\circ}, 17.70^{\circ}$ and $22.80^{\circ}$ decreased; the peak at $17.7^{\circ}$ disappeared when pressure attained $135 \mathrm{MPa}$, which contributed to a loss in crystallinity [17]. Following HPH treatment at 150 and $180 \mathrm{MPa}$, all XRD peaks became very weak except for a strong peak at $16.99^{\circ}$, suggesting a B-type starch. Similar results were reported concerning the structure of pressurized maize starch (A-type) being transformed into B-type patterns [18]. The HPH not only affects the amorphous zone of starch granules, but also destroys its crystalline zone. This is probably due to cavitation induced by $\mathrm{HPH}$-cavities filled with gas or vapor take shape as pressure decreases and collapse immediately when the pressure increases once more. High pressure gradients and high local velocities of liquid layers are induced in the vicinity of cavitation bubbles with their sudden collapse, which destroys the original structure of starch $[19,20]$. Additionally, cavitation decomposes water into $\mathrm{OH}$ radicals and $\mathrm{H}$ atoms and induces further interaction between radicals and starch molecules, thus transforming their structure [7].

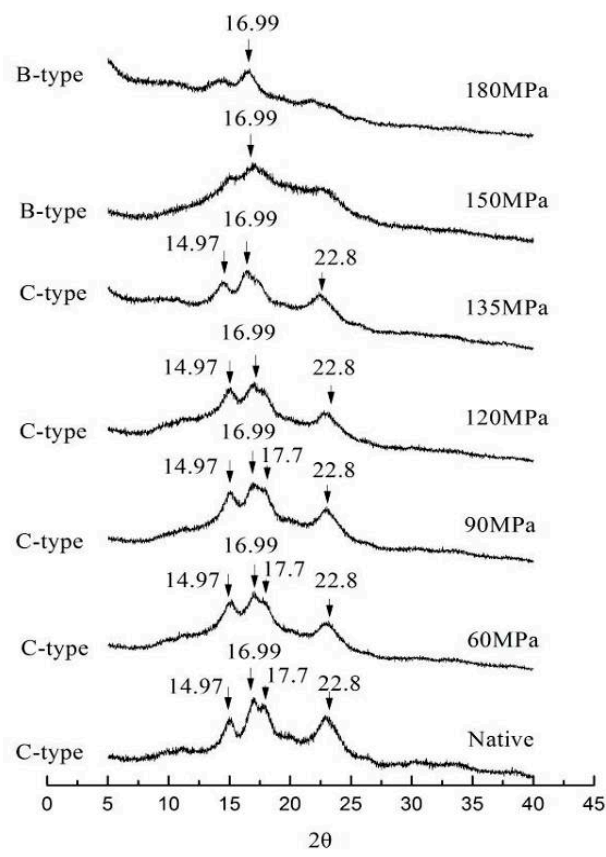

Figure 1. X-ray powder diffraction patterns of native and pressurized lotus seed starch.

\subsection{FTIR Analysis}

The FTIR was used to detect changes in starch structure on the molecular level. The FTIR spectrum changes can be divided into changes in band narrowing and in band intensity and relate to the ordering of specific conformations, such as the IR bands at $1022 \mathrm{~cm}^{-1}$ - that are thought to be related to short-range order of starch [21]. In the current investigation, the absorbance ratio of $1022 / 995 \mathrm{~cm}^{-1}$ was used as an index of structure order. The higher is the molecular order of starch double-helices structure, the lower is the absorbance ratio of $1022 / 995 \mathrm{~cm}^{-1}$ [22]. The absorbance ratio of $1022 / 995 \mathrm{~cm}^{-1}$ increased as pressure was elevated (Table 1). This suggested that HPH destroyed starch structure and reduced their short-range order. Meanwhile, pressure-dependent band narrowing emerged at around $3400 \mathrm{~cm}^{-1}$ (Figure 2), further indicating that starch structure was seriously affected by $\mathrm{HPH}$ treatment. These results were in accordance with the XRD results. 
Table 1. Thermal properties, particle size and Fourier transformed infrared spectroscopy (FTIR) ratio of Native and pressurized LS.

\begin{tabular}{ccccccc}
\hline Pressure & $\mathbf{1 0 2 2} / \mathbf{9 9 5} \mathbf{c m}^{\mathbf{- 1}}$ & $\mathbf{D}(\mathbf{3 , 2} \mathbf{2}$ & To & Tp & Tc & $\mathbf{\Delta H}$ \\
\hline Native & $0.85 \pm 0.06^{\mathrm{b}}$ & $11.50 \pm 1.80^{\mathrm{e}}$ & $69.01 \pm 0.11^{\mathrm{a}}$ & $72.68 \pm 0.21^{\mathrm{a}}$ & $83.00 \pm 0.34^{\mathrm{a}}$ & $13.28 \pm 0.41^{\mathrm{a}}$ \\
60 & $0.97 \pm 0.05^{\mathrm{a}, \mathrm{b}}$ & $12.00 \pm 1.50^{\mathrm{d}, \mathrm{e}}$ & $68.43 \pm 0.30^{\mathrm{a}}$ & $71.99 \pm 0.21^{\mathrm{b}}$ & $82.45 \pm 0.44^{\mathrm{a}}$ & $9.94 \pm 0.35^{\mathrm{b}}$ \\
90 & $0.97 \pm 0.09^{\mathrm{a}}$ & $12.10 \pm 1.84^{\mathrm{d}, \mathrm{e}}$ & $66.01 \pm 0.24^{\mathrm{b}}$ & $71.49 \pm 0.07^{\mathrm{c}}$ & $78.66 \pm 0.25^{\mathrm{b}}$ & $8.89 \pm 0.50^{\mathrm{c}}$ \\
120 & $0.98 \pm 0.07^{\mathrm{a}}$ & $16.20 \pm 2.10^{\mathrm{c}, \mathrm{d}}$ & $65.70 \pm 0.21^{\mathrm{b}, \mathrm{c}}$ & $70.74 \pm 0.16^{\mathrm{d}}$ & $76.35 \pm 0.42^{\mathrm{c}}$ & $7.07 \pm 1.27^{\mathrm{d}}$ \\
135 & $1.03 \pm 0.06^{\mathrm{a}}$ & $18.10 \pm 3.20^{\mathrm{b}, \mathrm{c}}$ & $65.22 \pm 0.49^{\mathrm{c}}$ & $70.49 \pm 0.28^{\mathrm{d}}$ & $75.64 \pm 0.27^{\mathrm{c}}$ & $5.33 \pm 0.10^{\mathrm{e}}$ \\
150 & $1.00 \pm 0.04^{\mathrm{a}}$ & $22.70 \pm 2.70^{\mathrm{a}, \mathrm{b}}$ & $51.82 \pm 0.61^{\mathrm{d}}$ & $56.59 \pm 0.41^{\mathrm{e}}$ & $59.92 \pm 1.00^{\mathrm{d}}$ & $5.18 \pm 0.12^{\mathrm{e}}$ \\
180 & $1.00 \pm 0.05^{\mathrm{a}}$ & $21.00 \pm 2.65^{\mathrm{a}}$ & $49.41 \pm 0.36^{\mathrm{e}}$ & $56.22 \pm 0.09^{\mathrm{e}}$ & $56.75 \pm 0.44^{\mathrm{e}}$ & $5.08 \pm 0.18^{\mathrm{e}}$ \\
\hline
\end{tabular}

Experimental data are expressed as mean $\pm \mathrm{SD}(n=3)$. Different letter following the values within the same column present significant differences $(p<0.05)$.

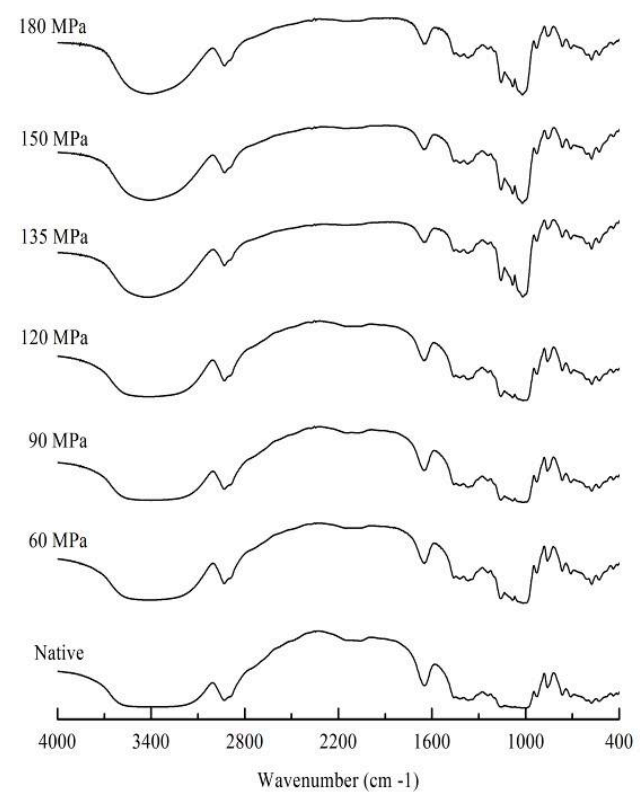

Figure 2. Fourier transformed infrared spectroscopy (FTIR) of native and pressurized LS.

\subsection{Morphology}

There was an evident change in the starch morphology when subjected to HPH. Most of the native starch granules had an elliptical shape with a smooth surface and most retained their granule structure in $\mathrm{HPH}$-treated starch up to $60 \mathrm{MPa}$ (Figure 3). However, during treatment at $90 \mathrm{MPa}$, some ruptured starch granules had slightly swollen surfaces and aggregated with other granules, forming gel-like structures; this became more pronounced when pressure reached $120 \mathrm{MPa}$, indicating that granule structure was destroyed by the $\mathrm{HPH}$. At $135 \mathrm{MPa}$ of treatment there were obvious changes in diffraction peaks (Figure 1, $135 \mathrm{MPa}$ ), and LS showed significant deformation and partial gelatinization, as the HPH linearly increased the water temperature [23,24]. A large proportion of granules may have contained two different regions: the outer region remaining unchanged while the internal region was significantly altered. When pressure exceeded $150 \mathrm{MPa}$, all granules lost their normal granule structure and broke into fragments, showing "broken porcelain-like" structures. In addition to the cavitation mentioned above, there were two other reasons for granule degradation induced by HPH: (1) shear forces induced by HPH can interrupt covalent bonds that bind the starch chains, as long as the chains are beyond a critical value, in what is known as mechano-chemical action of $\mathrm{HPH}$; and (2) changes of pressure result in rapid, instantaneous temperature increases in the thin liquid layers adjoining cavities, thus polymers are unavoidably pyrolyzed [19]. Not only cavitation, but shear and turbulence induced by high pressure also increase as homogenizing pressure rises, which makes breaking of polymers much easier [25-27]. This suggests that HPH is a good method for modifting starch. 


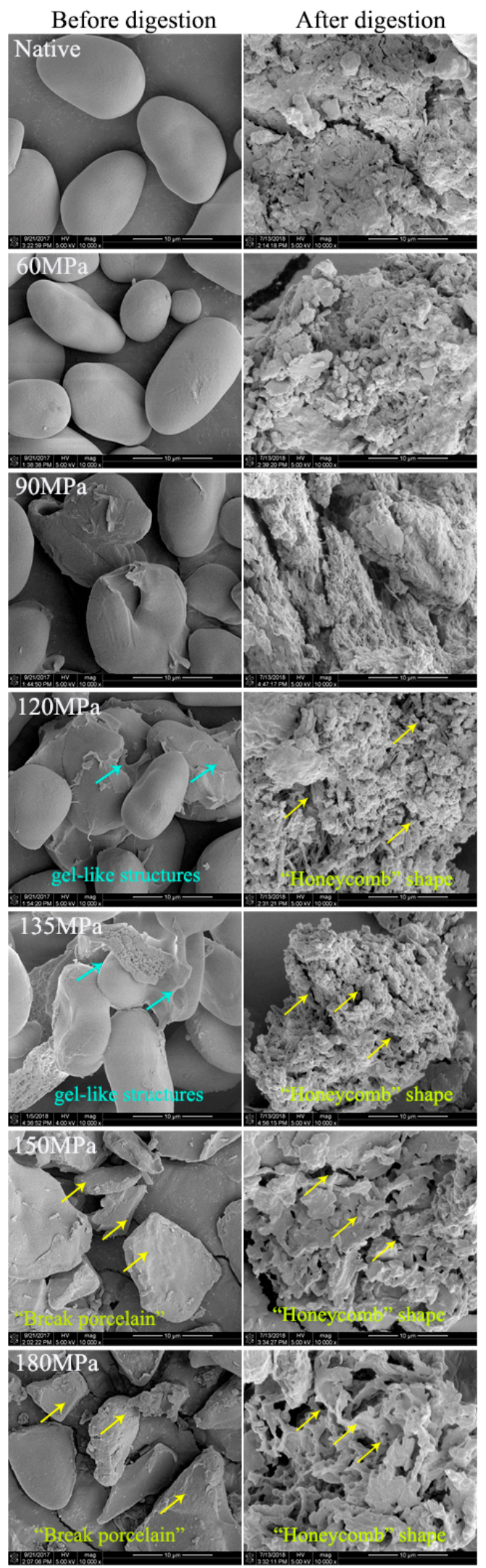

Figure 3. Scanning electron microscopy (SEM) of native and pressurized LS before digestion $(10,000 \times)$ and after digestion $(10,000 \times)$ in the DIVRSD (dynamic in vitro rat stomach system) model for $180 \mathrm{~min}$. 


\subsection{SP of Starch Granules}

The SP and solubility provide information for assessing the degree of interaction between starch chains within the amorphous and crystalline domains of the starch granule. There was a significant increase in SP of all samples at $75{ }^{\circ} \mathrm{C}$ (Figure 4), indicating that starch molecules combined with water molecules activated by heat and gelatinization occurred. Obviously, the SP of HPH-treated samples would gradually increase with rising pressure at any temperature stage, suggesting that $\mathrm{HPH}$ can advance water transfer into starch granules and therefore further influence the swelling of amorphous regions. This is consistent with previous studies [17,23], showing that starch granules being homogenized can absorb a great deal of water and swell rapidly. Because of the higher SP described above, starch granules were more vulnerable to shear stress induced by HPH, with some amylose leaching out even though starch retained granular structures and thus showed greater solubility than native starch (Figure 4a). The amount of soluble carbohydrate increased markedly at $75{ }^{\circ} \mathrm{C}$ due to the irreversible rupturing of starch granules. The ruptured fragments tended to readily form aggregates during heat-induced gelatinization. Treatment with HPH has been shown to dissociate solution aggregates [28]. Some amylopectin may be decomposed into amylose by HPH, which also contributes to the pressure-dependent increasing of solubility (Figure $4 \mathrm{~b}$ ).

The average size distribution of starch particles under different HPH conditions is shown in Table 1. $\mathrm{D}(3,2)$ (area mean diameter.)represents the area mean diameter. The starch granule size increased as pressure was elevated. This was the result of the high pressure and instantaneous temperature rise mentioned in relation to SEM and, under their influence, starch granules can absorb a great deal of water and rapidly swell, causing the size increase. Similar results were previously reported [17,23], in which pressurized starch showed a pronounced size increase compared to native cassava starch. Although the increased shear force induced by high pressure produced some smaller pieces in our study, there was only a non-significant decrease in particle size. This is consistent with the SEM results.

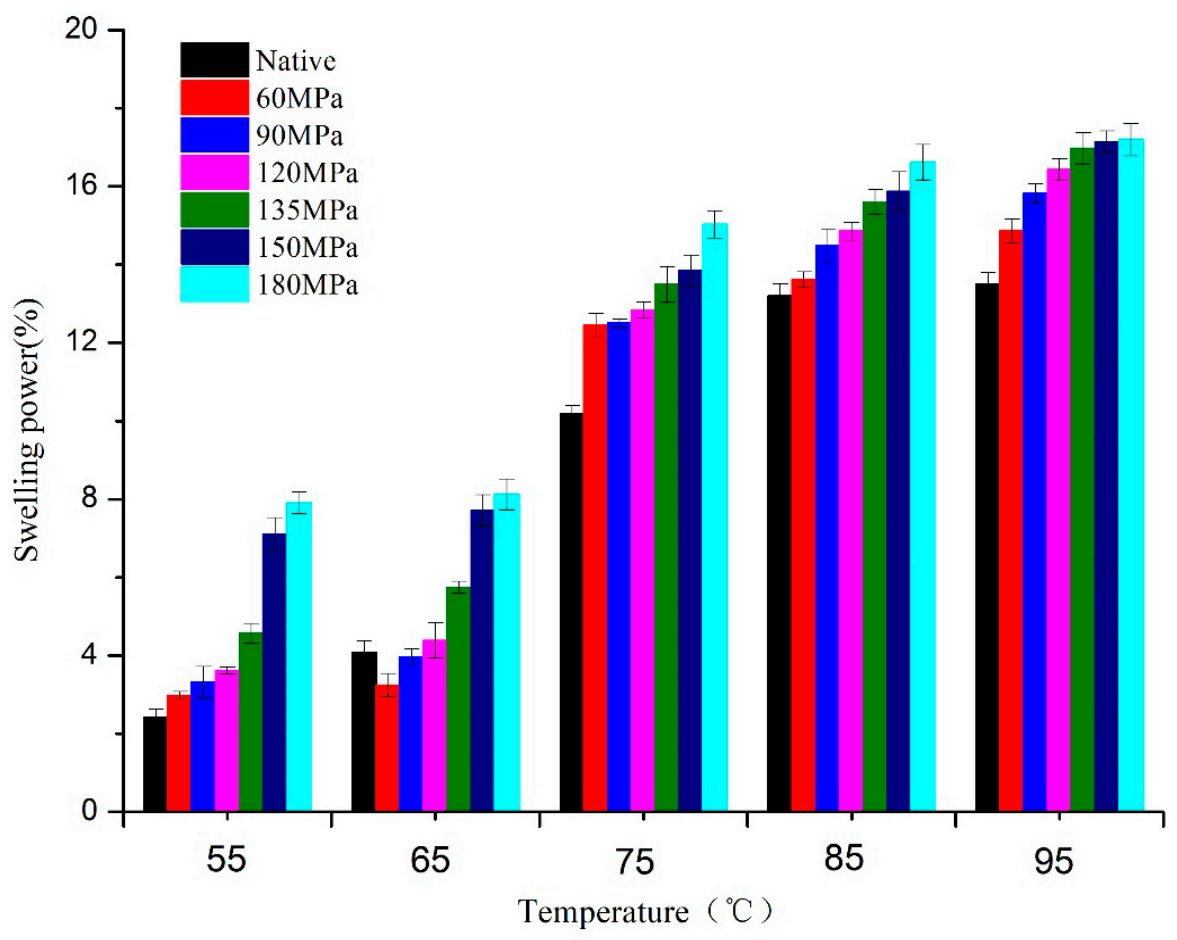

(a)

Figure 4. Cont. 


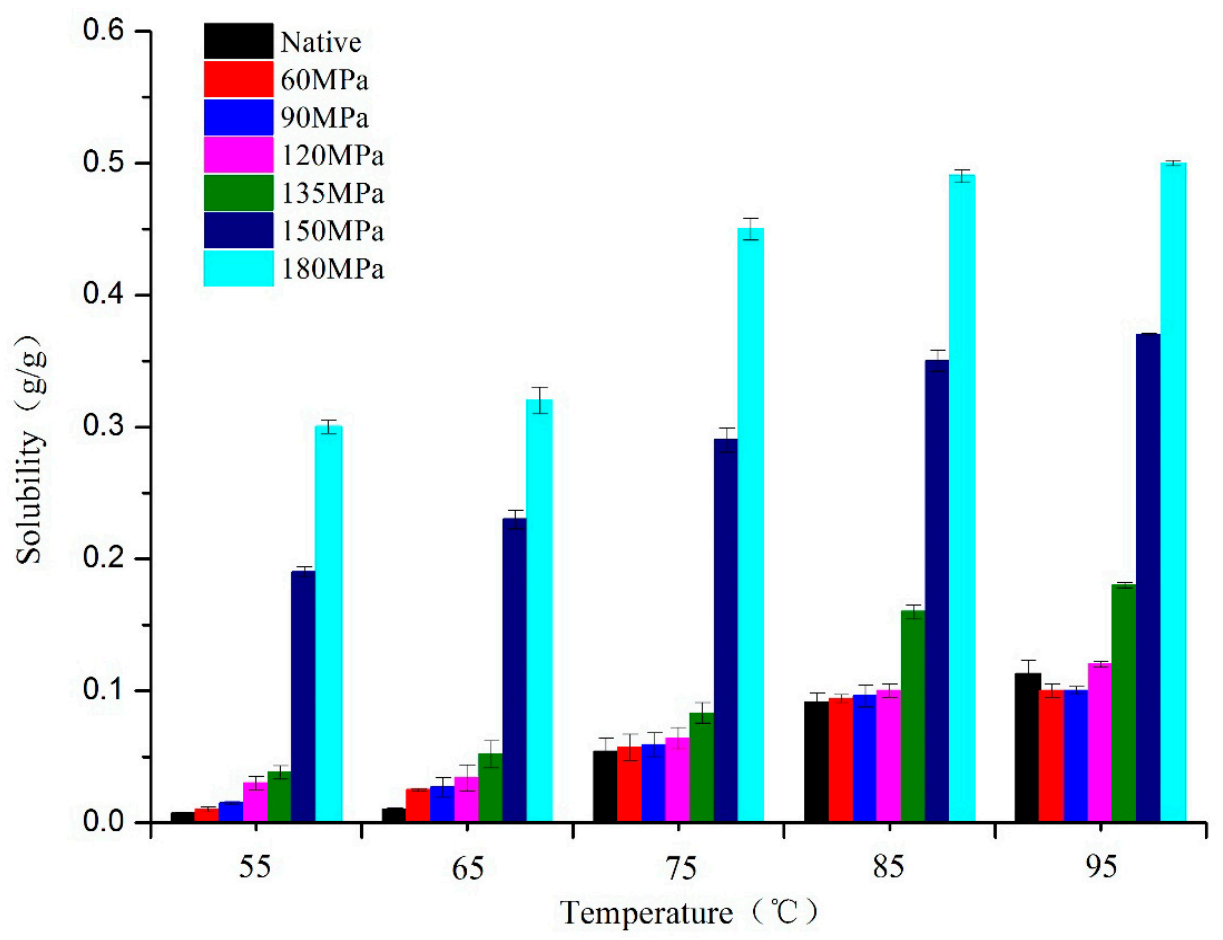

(b)

Figure 4. Swelling power (a) and solubility (b) of native and pressurized LS.

\subsection{Pasting Properties}

The $6 \%(w / v)$ homogenized-starch suspensions were determined by RVA and their pasting properties are summarized in Figure 5. The peak viscosity (PV), trough viscosity (TV), and final viscosity (FV) values of $\mathrm{HPH}$-treated (120-180 MPa) starch gradually decreased as the pressure increased, except for 60 and $90 \mathrm{MPa}$. At pressures above $120 \mathrm{MPa}$, peaktime (PT) was not detected, suggesting destruction of the crystalline region inside the starch. This may be due to starch granule changes during the re-formation of crystalline structures $[13,29]$. The increasing temperature and cavitation induced by HPH hastened the movement of molecules, and so accelerated reactions between starch molecules, therefore starch gelatinization occurs However, cavitation, shear and turbulence phenomena became even larger as homogenizing pressure increased, which destroyed intermolecular bonding between starch molecules and so could interrupt covalent bonds that bound the chains of starch, especially double-helical structures of amylopectin crystallites, as long as the chains exceeded a critical value $[30,31]$. The water molecules also acted as diluents, not only interrupting aggregation of starch molecules of low viscosity, but providing a chance for granules to react with them. This finally transformed the native C-type into a B-type pattern as described for the XRD. 


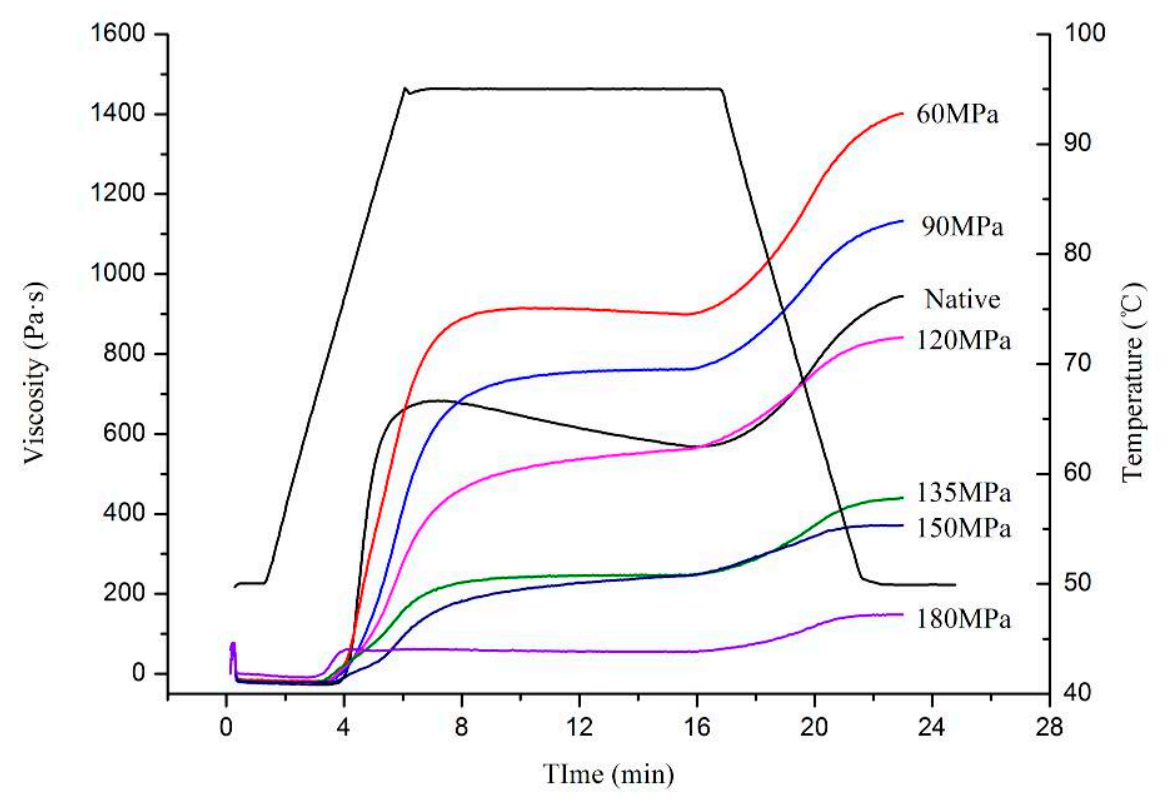

Figure 5. Pasting properties of native and pressurized LS.

\subsection{Thermal Properties}

The thermal properties of native and HPH-treated LS were measured using a DSC (Table 1). There was a considerable reduction in the values (To, Tp, Tc, and $\Delta \mathrm{H}$ ) of HPH-treated (60-180 MPa) starch compared to native LS, indicating that granule hydration occurred with HPH treatment. This was in accordance with the SEM results. The $\Delta \mathrm{H}$ represents the thermal energy needed to melt double-helical structures of amylopectin crystallites [32]. The HPH treatment advanced the double-helical dissociation, weakening the molecular order and crystalline structure. In contrast, native starch samples need higher energy to destroy intermolecular bonding between water and starch molecules, such as hydrogen bonds and starch crystallites [33]. Additionally, HPH treatment of $>150 \mathrm{MPa}$ changed the XRD of starch to a B-type pattern (Figure 1). The B-type starches tend to exhibit lower transition temperatures and enthalpy [34,35]. The DSC investigation further indicated that HPH may be a superior method for starch modification.

\subsection{Starch Digestion by DIVRSD-II}

The digestion efficiency of HPH-treated starch was compared with native LS. The enzyme susceptibility of HPH-treated starch was higher than that of native LS and was in the following order: $180>150>135>120>90>60 \mathrm{MPa}>$ native starch (Figure 6). Digestion efficiency of starch relies on various factors, such as size and damage degree of granule, crystallinity and proportions of acmylose and amylopectin [36,37]. Native starch had a much higher degree of crystallinity, as well as double-helical order and so its digestibility was lower than HPH-treated starch, even if the $\mathrm{HPH}$ treatment had somewhat increased the starch granule size. Also, amylose molecules tend to be amorphous in starch granules and high shear forces of $\mathrm{HPH}$ were shown to disrupt the integrity of starch granules and decompose some amylopectin into amylose [26]. These were all reasons for the higher digestion efficiency of HPH-treated starch. 


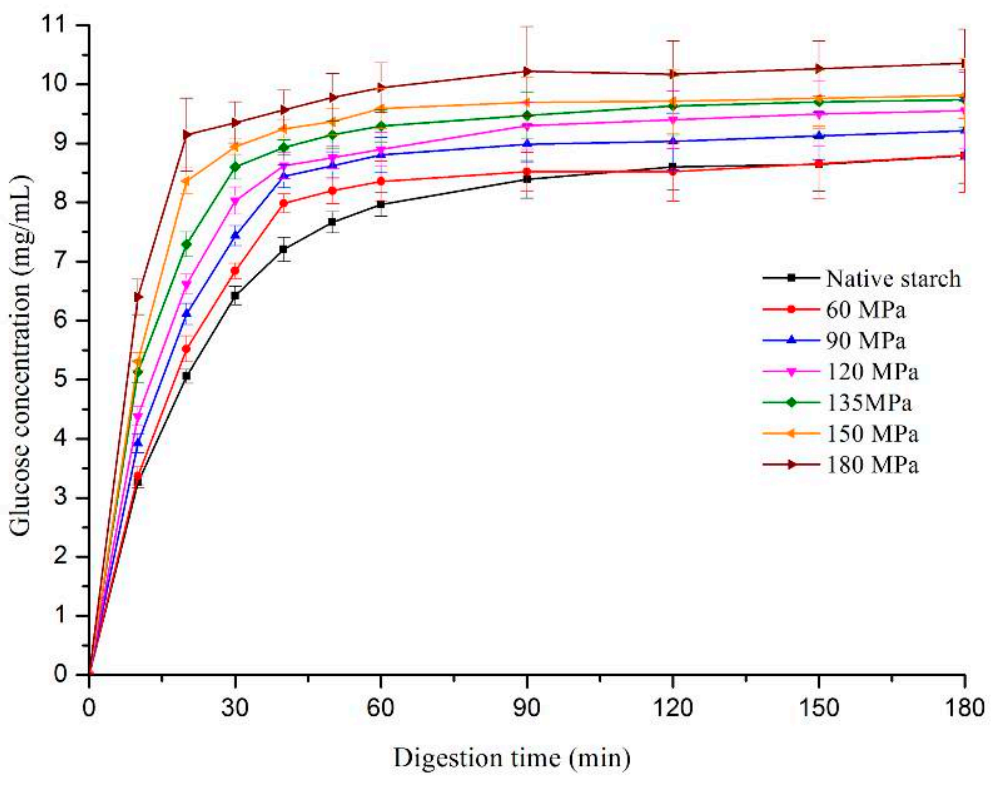

Figure 6. Digestion efficiency of native and pressurized LS.

Great variation between native and HPH-treated starch was observed in SEM micrographs (Figure 3). After $180 \mathrm{~min}$ of digestion, a large amount of small detritus appeared on the surface of dense particles of native starch, indicating enzymolysis. There were no significant changes in starch with moderate $\mathrm{HPH}$ treatment $(60 \mathrm{MPa})$ compared to native starch, consistent with the digestion efficiency. However, for pressure $>90 \mathrm{MPa}$, the small detritus was replaced by holes of varied sizes on the surface and in the interior of granules, showing an irregular "honeycomb" shape and loose organizational structure-with greater pressure, the voids were larger. This was due to severe damage to the crystalline and amorphous regions of starch with $\mathrm{HPH}$, leaving both inside and outside of the fragments more vulnerable to amylase and resulting in higher digestion efficiency compared with native starch.

Due to the high efficiency and the dramatically greater yield of modified starch, we believe that $\mathrm{HPH}$ has a great potential for academic and industrial research activity. It is an effective technique for modified starch preparation and a new strategy for process intensification, enhancing competition of industries to be more economic and innovative.

\section{Conclusions}

In this study, the effects of HPH treatment (up to $180 \mathrm{MPa}$ ) on the physicochemical and digestion properties of LS were investigated. Cavitation, shear and turbulence induced by high pressure caused irreversible distortion to crystalline and amorphous regions of LS, thus transforming the C-type into B-type starch structure and exhibiting lower transition temperatures and enthalpy. The absorbance ratio of 1022/995 $\mathrm{cm}^{-1}$, as an index of structure order, showed a pressure-dependent increase for FTIR, indicating severe damage of pressurized LS short-range order. The SEM showed evident change in starch morphology, with aggregation of ruptured starch granules, forming gel-like structures following $>90 \mathrm{MPa} \mathrm{HPH}$. However, at >150 MPa, granules broke into fragments, showing "broken porcelain-like" structures. The LS absorbed a great deal of water during HPH treatment and rapidly swelled, thereby increasing size distribution of pressurized LS and showing increased SP and solubility. The RVA analysis showed that most pressurized LS had a lower viscosity than native starch, because starch chains, especially double-helical structures of amylopectin crystallites were broken by cavitation, shear and turbulence phenomena. The severe damage to starch granules as well as the lower degree of double-helical order resulted in higher digestion efficiency of LS under the DIVRSD-II model. Additionally, both the inside and outside of starch fragments were vulnerable to amylase and the 
residues exhibited an irregular "honeycomb" shape in morphology and the amount of residual starch decreased with increased pressure.

Author Contributions: The acquisition, analysis and interpretation of data, Z.G.; writing-Review \& Editing, B.Z.; The creation of new software used in the work, L.C.; Conception and design of the work, B.Z.

Funding: This research received no external funding.

Acknowledgments: The authors gratefully acknowledge the financial support from the International Science and Technology Cooperation and Exchange Project of Fujian Agriculture and Forestry University (KXGH17001), the FAFU Funds for Distinguished Young Scientists (xjq201618), and the Research Fund of Guangxi Key Laboratory of Agricultural Resources Chemistry and Biotechnology (KF03).

Conflicts of Interest: The authors declare no conflict of interest.

\section{References}

1. Hung, P.V.; Maeda, T.; Morita, N. Study on Physicochemical Characteristics of Waxy and High-amylose Wheat Starches in Comparison with Normal Wheat Starch. Starch Stärke 2010, 59, 125-131. [CrossRef]

2. Tian, S.J.; Rickard, J.E.; Blanshard, J.M.V. Physicochemical Properties of Sweet Potato Starch. J. Sci. Food Agric. 2010, 57, 459-491. [CrossRef]

3. Zhang, Y.; Zeng, H.L.; Wang, Y.; Zeng, S.X.; Zheng, B.D. Structural characteristics and crystalline properties of lotus seed resistant starch and its prebiotic effects. Food Chem. 2014, 114, 9613-9644. [CrossRef] [PubMed]

4. Yu, H.; Cheng, L.; Yin, J.; Yan, S.; Liu, K.; Zhang, F.; Xu, B.; Li, L. Structure and physicochemical properties of starches in lotus (Nelumbo nucifera Gaertn.) rhizome. Food Sci. Nutr. 2013, 1, 273-283. [CrossRef] [PubMed]

5. Chen, B.; Guo, Z.; Zeng, S.; Tian, Y.; Miao, S.; Zheng, B. Paste structure and rheological properties of lotus seed starch glycerin monostearate complexes formed by high-pressure homogenization. Food Res. Int. 2018, 103, 380-389. [CrossRef] [PubMed]

6. Chen, B.; Zeng, S.; Zeng, H.; Guo, Z.; Zhang, Y.; Zheng, B. Properties of lotus seed starch-glycerin monostearin complexes formed by high pressure homogenization. Food Chem. 2017, 226, 119-127. [CrossRef] [PubMed]

7. Wang, B.; Li, D.; Wang, L.J.; Yu, L.C.; Chen, X.D.; Mao, Z.H. Effect of high-pressure homogenization on the structure and thermal properties of maize starch. J. Food Eng. 2008, 87, 436-444. [CrossRef]

8. Guerra, A.; Etienne-Mesmin, L.; Livrelli, V.; Denis, S.; Blanquet-Diot, S.; Alric, M. Relevance and challenges in modeling human gastric and small intestinal digestion. Trends Biotechnol. 2012, 30, 591-600. [CrossRef]

9. Menard, O.; Cattenoz, T.; Guillemin, H.; Souchon, I.; Deglaire, A.; Dupont, D.; Picque, D. Validation of a new in vitro dynamic system to simulate infant digestion. Food Chem. 2014, 145, 1039-1045. [CrossRef]

10. Chen, $\mathrm{L}$; $\mathrm{Wu}, \mathrm{X}$;; Chen, X.D. Comparison between the digestive behaviors of a new in vitro rat soft stomach model with that of the in vivo experimentation on living rats-Motility and morphological influences. J. Food Eng. 2013, 117, 183-192. [CrossRef]

11. $\mathrm{Wu}, \mathrm{P}$; $\mathrm{Chen}, \mathrm{L} . ; \mathrm{Wu}, \mathrm{X} . ; \mathrm{C}$ en, X.D. Digestive behaviours of large raw rice particles in vivo and in vitro rat stomach systems. J. Food Eng. 2014, 142, 170-178. [CrossRef]

12. Guo, Z.; Jia, X.; Miao, S.; Chen, B.; Lu, X.; Zheng, B. Structural and thermal properties of amylose-fatty acid complexes prepared via high hydrostatic pressure. Food Chem. 2018, 264, 172-179. [CrossRef] [PubMed]

13. Guo, Z.; Zeng, S.; Lu, X.; Zhou, M.; Zheng, M.; Zheng, B. Structural and physicochemical properties of lotus seed starch treated with ultra-high pressure. Food Chem. 2015, 186, 223-230. [CrossRef] [PubMed]

14. Wu, P.; Deng, R.; Wu, X.; Wang, Y.; Dong, Z.; Dhital, S.; Chen, X.D. In vitro gastric digestion of cooked white and brown rice using a dynamic rat stomach model. Food Chem. 2017, 237, 1065-1072. [CrossRef] [PubMed]

15. Wu, P.; Bhattarai, R.R.; Dhital, S.; Deng, R.; Chen, X.D.; Gidley, M.J. In vitro digestion of pectin- and mango-enriched diets using a dynamic rat stomach-duodenum model. J. Food Eng. 2017, 202, 65-78. [CrossRef]

16. Zhang, X.; Liao, Z.; Wu, P.; Chen, L.; Chen, X.D. Effects of the gastric juice injection pattern and contraction frequency on the digestibility of casein powder suspensions in an in vitro dynamic rat stomach made with a 3D printed model. Food Res. Int. 2018, 106, 495-502. [CrossRef] [PubMed]

17. Li, G.; Niu, K.; Hou, H.; Zhang, H.; Dai, Y.; Dong, H. Effects of homogenizing pressure on mechanochemical properties of corn starch. Trans. Chin. Soc. Agric. Eng. 2017, 33, 271-277. 
18. Katopo, H.; Song, Y.; Jane, J.L. Effect and mechanism of ultrahigh hydrostatic pressure on the structure and properties of starches. Carbohydr. Polym. 2002, 47, 233-244. [CrossRef]

19. Che, L.M.; Wang, L.J.; Li, D.; Bhandari, B.; Özkan, N.; Chen, X.D.; Mao, Z.H. Starch pastes thinning during high-pressure homogenization. Carbohydr. Polym. 2009, 75, 32-38. [CrossRef]

20. Freudig, B.; Tesch, S.; Schubert, H. Production of Emulsions in High-Pressure Homogenizers-Part II: Influence of Cavitation on Droplet Breakup. Eng. Life Sci. 2010, 3, 266-270. [CrossRef]

21. Wang, S.; Wang, J.; Zhang, W.; Li, C.; Yu, J.; Wang, S. Molecular order and functional properties of starches from three waxy wheat varieties grown in China. Food Chem. 2015, 181, 43-50. [CrossRef] [PubMed]

22. Man, J.; Yang, Y.; Zhang, C.; Zhou, X.; Dong, Y.; Zhang, F.; Liu, Q.; Wei, C. Structural changes of high-amylose rice starch residues following in vitro and in vivo digestion. J. Agric. Food Chem. 2012, 60, 9332-9341.

23. Che, L.; Li, D.; Wang, L.; Oezkan, N.; Chen, X.D.; Mao, Z. Effect of high-pressure homogenization on the structure of cassava starch. Int. J. Food Prop. 2007, 10, 911-922. [CrossRef]

24. Ekpeni, L.E.N.; Benyounis, K.Y.; Nkem-Ekpeni, F.F.; Stokes, J.; Olabi, A.G. Underlying factors to consider in improving energy yield from biomass source through yeast use on high-pressure homogenizer $(\mathrm{HPH})$. Energy 2015, 81, 74-83. [CrossRef]

25. Augusto, P.E.D.; Ibarz, A.; Cristianini, M. Effect of high pressure homogenization (HPH) on the rheological properties of tomato juice: Creep and recovery behaviours. Food Res. Int. 2013, 54, 169-176. [CrossRef]

26. Paquin, P. Technological properties of high pressure homogenizers: The effect of fat globules, milk proteins, and polysaccharides. Int. Dairy J. 1999, 9, 329-335. [CrossRef]

27. Song, X.Z.; Zhou, C.J.; Wu, Q.L.; Fu, F.; Chen, Z.L. Effect of high-pressure homogenization on particle size and film;properties of soy protein isolate. Ind. Crops Prod. 2013, 43, 538-544. [CrossRef]

28. Knorr, D.; Froehling, A.; Jaeger, H.; Reineke, K.; Schlueter, O.; Schoessler, K. Emerging technologies in food processing. Annu. Rev. Food Sci. Technol. 2011, 2, 203-235. [CrossRef] [PubMed]

29. Li, W.; Zhang, F.; Liu, P.; Bai, Y.; Lin, G.; Shen, Q. Effect of high hydrostatic pressure on physicochemical, thermal and morphological properties of mung bean (Vigna radiata L.) starch. J. Food Eng. 2011, 103, 388-393. [CrossRef]

30. Shi, A.M.; Li, D.; Wang, L.J.; Li, B.Z.; Adhikari, B. Preparation of starch-based nanoparticles through high-pressure homogenization and miniemulsion cross-linking: Influence of various process parameters on particle size and stability. Carbohydr. Polym. 2011, 83, 1604-1610. [CrossRef]

31. Wei, B.; Cai, C.; Xu, B.; Jin, Z.; Tian, Y. Disruption and molecule degradation of waxy maize starch granules during high pressure homogenization process. Food Chem. 2018, 240, 165-173. [CrossRef] [PubMed]

32. Xiao, H.; Lin, Q.; Liu, G.Q.; Yu, F. Evaluation of Black Tea Polyphenol Extract Against the Retrogradation of Starches from Various Plant Sources. Molecules 2012, 17, 8147-8158. [CrossRef] [PubMed]

33. Guo, Z.; Zeng, S.; Zhang, Y.; Lu, X.; Tian, Y.; Zheng, B. The effects of ultra-high pressure on the structural, rheological and retrogradation properties of lotus seed starch. Food Hydrocoll. 2015, 44, 285-291. [CrossRef]

34. Zhang, K.; Qiyu, L.U. Relationship between the type-A and type-B starch and the gelatinization characteristics of wheat flour. J. Henan Univ. Technol. 2016, 37, 18-22.

35. Zobel, H.F. Molecules to Granules: A Comprehensive Starch Review. Starch Stärke 1988, 40, 44-50. [CrossRef]

36. Huang, J.; Lin, L.; Wang, J.; Wang, Z.; Liu, Q.; Wei, C. Invitro digestion properties of heterogeneous starch granules fromhigh-amylose rice. Food Hydrocoll. 2016, 54, 10-22. [CrossRef]

37. Svihus, B.; Hervik, A.K. Digestion and metabolic fates of starch, and its relation to major nutrition-related health problems: A review. Starch Stärke 2016, 68, 302-313. [CrossRef]

(C) 2019 by the authors. Licensee MDPI, Basel, Switzerland. This article is an open access article distributed under the terms and conditions of the Creative Commons Attribution (CC BY) license (http://creativecommons.org/licenses/by/4.0/). 